\title{
High-resolution habitat suitability model for Phlebotomus pedifer, the vector of cutaneous leishmaniasis in southwestern Ethiopia
}

\author{
Myrthe Pareyn ${ }^{1 *}$,, Anneleen Rutten ${ }^{1 \dagger}$, Behailu Merdekios ${ }^{2 \dagger}{ }^{\dagger}$, Ronja E. M. Wedegärtner ${ }^{3}$, Nigatu Girma ${ }^{4}$, \\ Leo Regelbrugge ${ }^{1}$, Simon Shibru ${ }^{4}$ and Herwig Leirs ${ }^{1 *}$
}

\begin{abstract}
Background: Phlebotomus pedifer is the vector for Leishmania aethiopica causing cutaneous leishmaniasis (CL) in southwestern Ethiopia. Previous research on the transmission dynamics of $\mathrm{CL}$ resulted in recommendations for vector control. In order to target these interventions towards affected areas, a comprehensive understanding of the spatial distribution of $P$. pedifer at high spatial resolution is required. Therefore, this study determined the environmental predictors that facilitate the distribution of $P$. pedifer and created a map indicating the areas where conditions are suitable for survival of the vector in southwestern Ethiopia with high spatial resolution.
\end{abstract}

Methods: Phlebotomus pedifer presence points were collected during two entomological surveys. Climate, vegetation and topographic variables were assembled. Climate variables were interpolated with variables derived from high-resolution digital elevation models to generate topoclimatic layers representing the climate conditions in the highlands. A Maximum Entropy model was run with the presence points, predicting variables and background points, which were selected based on a bias file.

Results: Phlebotomus pedifer was the only captured Phlebotomus species in the study area and was collected at altitudes ranging between 1685 and $2892 \mathrm{~m}$. Model projections indicated areas with suitable conditions in a 'belt' surrounding the high mountain peaks. Model performance was high, with train and test AUC values being 0.93 and 0.90 , respectively. A multivariate environmental similarity surface (MESS) analysis showed that the model projection was only slightly extrapolated for some of the variables. The mean annual temperature was the environmental variable, which contributed most to the model predictions (60.0\%) followed by the seasonality in rainfall (13.2\%). Variables representing steep slopes showed very low importance to model predictions.

Conclusions: Our findings indicate that the suitable habitats for P. pedifer correspond well with the altitudes at which $\mathrm{CL}$ was reported previously, but the predictions are more widely distributed, in contrast with the description of $C L$ to occur in particular foci. Moreover, we confirm that vector distribution is driven by climate factors, suggesting inclusion of topoclimate in sand fly distribution models. Overall, our model provides a map with a high spatial resolution that can be used to target sand fly control measures in southwestern Ethiopia.

Keywords: Species distribution modeling, Maximum entropy, Sand fly, Phlebotomus pedifer, Ethiopia, Topoclimate, Downscaling, Cutaneous leishmaniasis

\footnotetext{
*Correspondence: myrthe.pareyn@uantwerpen.be; herwig.

leirs@uantwerpen.be

${ }^{\dagger}$ Anneleen Rutten and Behailu Merdekios contributed equally to this work

${ }^{1}$ Evolutionary Ecology Group, University of Antwerp, Antwerp, Belgium

Full list of author information is available at the end of the article
}

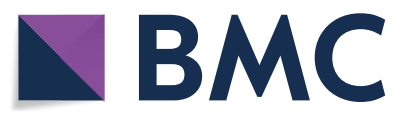

(c) The Author(s) 2020. This article is licensed under a Creative Commons Attribution 4.0 International License, which permits use, sharing, adaptation, distribution and reproduction in any medium or format, as long as you give appropriate credit to the original author(s) and the source, provide a link to the Creative Commons licence, and indicate if changes were made. The images or other third party material in this article are included in the article's Creative Commons licence, unless indicated otherwise in a credit line to the material. If material is not included in the article's Creative Commons licence and your intended use is not permitted by statutory regulation or exceeds the permitted use, you will need to obtain permission directly from the copyright holder. To view a copy of this licence, visit http://creativeco mmons.org/licenses/by/4.0/. The Creative Commons Public Domain Dedication waiver (http://creativecommons.org/publicdomain/ zero/1.0/) applies to the data made available in this article, unless otherwise stated in a credit line to the data. 


\section{Background}

Phlebotomine sand flies (Diptera: Phlebotominae) are tiny, hematophagous insects that occur in tropical and subtropical regions. In Africa, the genera Phlebotomus and Sergentomyia occur and some species of the former genus are the vector of Leishmania spp., causing leishmaniasis in humans [1]. The infection can manifest in three major clinical forms: cutaneous (CL), mucocutaneous (MCL) and visceral (VL) leishmaniasis, which are all three occurring in Ethiopia [2-4]. The most common form is CL, which is caused by Leishmania aethiopica. This parasite species is transmitted by Phlebotomus pedifer Lewis, Mutinga \& Ashford, 1972 in southwestern and P. longipes Parrot \& Martin, 1939 in central and northern Ethiopia [5-7].

In great contrast to the $878 \mathrm{CL}$ cases that were reported to the WHO in 2018, it is estimated that the incidence of the infection lies between 20,000-50,000 cases yearly, reflecting the severe underreporting of the infection in Ethiopia [4, 8]. CL particularly occurs in foci on the mountain slopes of the Ethiopian Rift Valley, ranging from North to Southwest and South to Northeast in the country. The described foci are all situated at altitudes ranging between $1700-2700 \mathrm{~m}$ and are located in four regional states: Southern Nations, Nationalities and Peoples' Region (SNNPR), Amhara, Tigray and Oromia, and Addis Ababa city administration [5, 6, 9-13].

Ochollo is a well-known CL focus at about $2100 \mathrm{~m}$ in southwestern Ethiopia and is considered a model village for research investigating the transmission dynamics of CL $[6,9,14]$. The area has a rough topography and is characterized by steep slopes, many rocks and basalt cliffs with caves, providing the ideal habitat for $P$. pedifer and the animal reservoir of the infection, hyraxes [15]. According to findings on the transmission cycle in Ochollo, suggestions have been made for vector control and disease prevention in the area $[6,9,14]$.

Effective and efficient implementation of integrated vector control programmes and resource allocation requires a comprehensive understanding of the spatial distribution of $P$. pedifer. Besides from Ochollo and an outbreak in Silte woreda, neither $P$. pedifer nor CL has been reported in the surrounding areas, even though the topography and ecology appear similar in some areas $[6$, $9,11,14,15]$. However, a recent study indicated many of these areas to be at high-risk for CL based on environmental parameters (rainfall, altitude and slope), yet no (entomological) surveys have been conducted here [16].

It is quite novel that species distribution models (SDMs) are being implemented to predict the distribution of a vector to optimize control measures [17]. SDMs are sophisticated, dynamic tools that can identify areas that are suitable for the survival of a particular species. It integrates species occurrence data and information about environmental conditions at these locations to characterize the niche of the species and project it into the geographical space, resulting in a map that predicts the species' potential distribution $[18,19]$.

Commonly, bioclimatic variables are applied in SDMs at 30 arc-second resolution $\left(1 \mathrm{~km}^{2}\right)$ or coarser, which represent free-air conditions that were averaged over the past 30 years [20-22]. Although these layers are probably adequate for flat terrains, they may not be sufficient for representation in mountainous areas with a variable topography [23-26]. Due to this vertical dimension, organisms experience microclimatic conditions, which can vary noticeably over a short distance. This is attributed to several topographic factors, such as slope angle, aspect, solar radiation, distance to the ocean, etc. [27]. An additional issue of these macroclimatic data is that other layers with a higher spatial resolution need to be resampled, which can lead to loss of important details.

However, macroclimatic data can be downscaled with variables derived from high-resolution digital elevation models (DEMs) to generate a statistical relationship that results in higher resolution climatic data [23, 24]. Integration of these high-resolution climatic variables was demonstrated to significantly improve the predictive power of SDMs $[28,29]$.

In this study, we used topoclimatic variables in an SDM to determine the environmental predictors that facilitate the presence of $P$. pedifer and assessed areas that are suitable for the survival of the vector with high spatial resolution in five zones of the SNNPR. The generated maps can be implemented by policymakers for guidance of targeted vector control programs to reduce the burden of CL in this area in southwestern Ethiopia.

\section{Methods}

\section{Site description}

The study was conducted in the SNNPR, in southwestern Ethiopia (Fig. 1a). The area has a variable topography with an altitude ranging from 340 to $3433 \mathrm{~m}$ (Fig. 1b). The south and west of the area comprise flat lowlands, whereas the north and east are mountainous. P. pedifer occurs in mountainous areas and the model village for research on CL transmission, Ochollo, is situated near Arba Minch, in Gamo zone. Therefore, we selected Gamo zone, three additional surrounding administrative zones, including Gofa, Wolaita and Dawuro and Dherashe area for sample collection (Fig. 1c). Together, the area covers approximately $22,000 \mathrm{~km}^{2}$ and is inhabited by 4.7 million people.

The study area consists of mountains and valleys with an altitude ranging between 550 and $3390 \mathrm{~m}$. Due to its 
topography, it has a temperate climate, with an average yearly temperature ranging from $9.3{ }^{\circ} \mathrm{C}$ to $25.5{ }^{\circ} \mathrm{C}$ and rainfall varying between $630 \mathrm{~mm}$ and $2280 \mathrm{~mm}$, in the lowlands and highlands [30]. Because the study area covers a wide topographical range, the seasons vary from place to place, but generally the dry season lasts from October to April and the wet season from May to September. In recent years, the area has been subjected to ecological modifications related to human activities, like urbanization, agriculture and deforestation.

\section{Occurrence data}

Occurrence points of $P$. pedifer were collected during two consecutive entomological surveys (Fig. 2, black frame, Fig. 3).

First, 76 presence points were assembled during an active case finding survey carried out from May to July 2018. The survey was performed under guidance of a neglected tropical diseases (NTD) focal person and health extension workers and by questioning community members about the presence of CL patients supported by pictures of lesions and hyraxes. When a suspected CL case was found, a CDC miniature light trap (John W. Hock Company, Gainesville, Florida, USA) was set in the late afternoon inside the patient's dwelling or in a nearby cave or rocky area where hyraxes were present. Sand flies were collected the next morning, mounted in CMCP-10 high viscosity mounting medium (Polysciences Europe, Herschberg, Germany) and the species was determined according to relevant morphological keys [31-33].

Secondly, an elementary Maximum Entropy (MaxEnt) model was developed using the $P$. pedifer presence points collected during the active case finding survey in 2018 and environmental layers that were found to predict the presence of CL in Ethiopia in a study of Seid et al. [16]: altitude, slope and rainfall. A multivariate environmental similarity surface (MESS) analysis was integrated, measuring the extent of the projected data, which was not within the range with the training variables (thus causing model extrapolation). We intended to keep the extent of extrapolation low as it informs on the credibility of the model output. Therefore, a new sampling approach was designed based a weighted overlay of the MESS analysis $(70 \%)$ and the distance to the road $(30 \%)$, in order to reduce the degree of extrapolation by additional sampling in accessible places. This entomological survey was carried out in the dry season (January and February 2020), when sampling sites were better accessible and a higher sand fly abundance was expected [15]. During this survey, we searched for suspected CL cases for nearby sand fly trapping. If $\mathrm{CL}$ cases were absent, traps were placed in other potential sand fly breeding or resting sites, because the area could still be at risk for an outbreak if the vector would be present. Collected specimens were processed as described above, leading to 23 additional $P$. pedifer presence points.

\section{Sampling bias file}

Most of the sampling effort was performed within a certain distance to the roads and towns (approximately $10 \mathrm{~km}$ ), which was necessary to ensure access to the sampling areas, particularly at rainy days. Moreover, case finding and sand fly trapping were never attempted at altitudes under $1400 \mathrm{~m}$. This is because neither $P$. pedifer nor CL have been observed at altitudes under $1700 \mathrm{~m}$. Additionally, we applied a buffer of $300 \mathrm{~m}$ in altitude to avoid missing sites where $P$. pedifer could be present on the one hand and prevent putting too much effort in sites where the vector cannot be found on the other hand.

In order to diminish spatial autocorrelation of the sampled presence points without reducing the predictive power of the model, a sampling bias file was designed

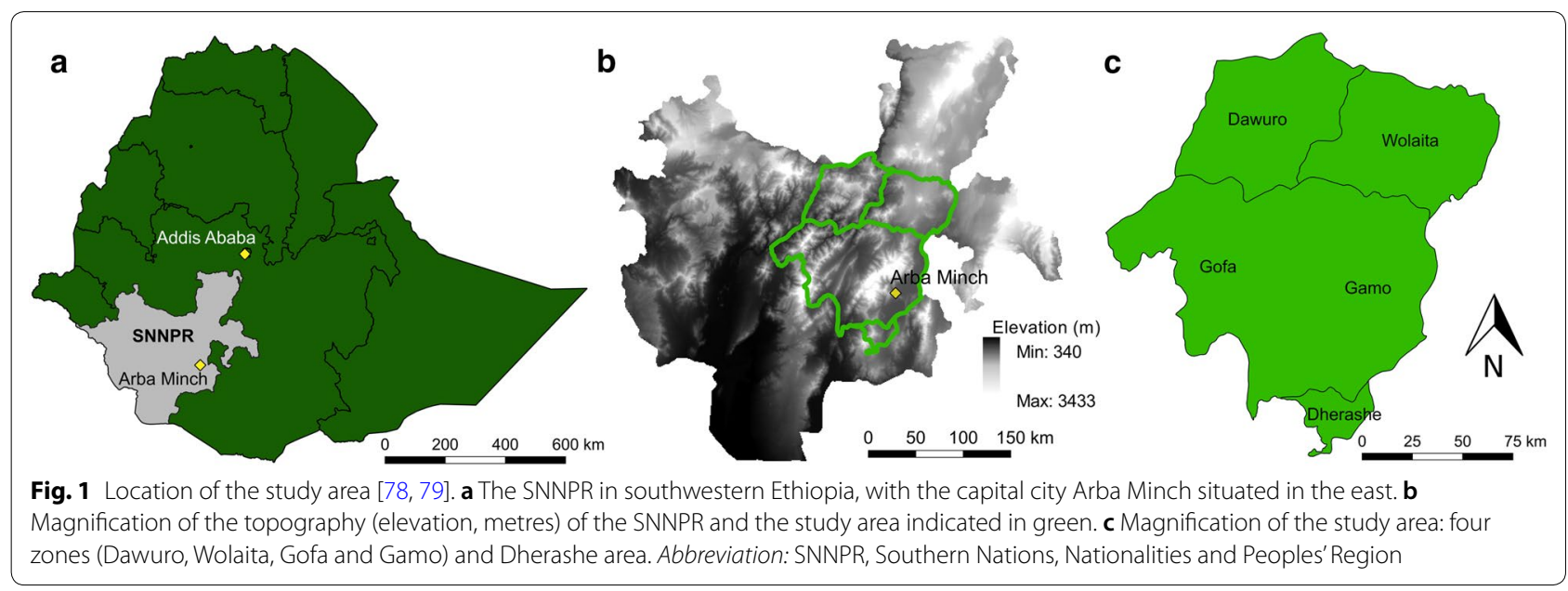


to match the sampling effort and avoid overfitting of the model (Fig. 2, dark grey frame, Fig. 3) [34]. Therefore, a weighted overlay was performed with increasing weights for proximity $(<2.5 \mathrm{~km}, 2.5-5 \mathrm{~km}, 5 \mathrm{~km}-10 \mathrm{~km}$, $>10 \mathrm{~km}$ ) to a town and road (50/50\%). All areas under $1400 \mathrm{~m}$ were given the lowest weight and the final raster file was used for selection of background points with an increased probability in areas with a high sampling effort (explained below).

\section{Environmental data}

\section{Collection of environmental data}

A wide range of environmental layers was acquired as candidate explanatory variables for the model (Fig. 2, light grey frame). Specifics and sources of the variables and the range in our study site are demonstrated in Table 1. All manipulations of the variable layers were carried out in ArcGIS version 10.4.1.

Because temperature and precipitation are relevant drivers for the distribution of $P$. pedifer, bioclimatic variables were derived from 'Climatologies at high resolution for the earth's land surface areas' (CHELSA, https://chels a-climate.org/bioclim/) with a spatial resolution of 30

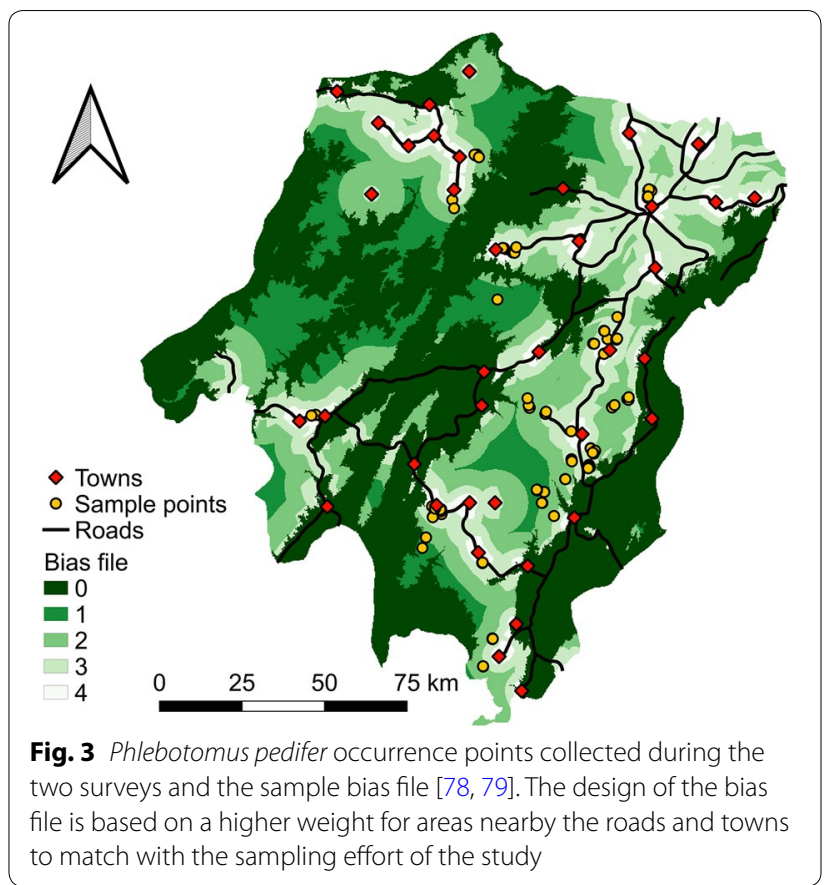

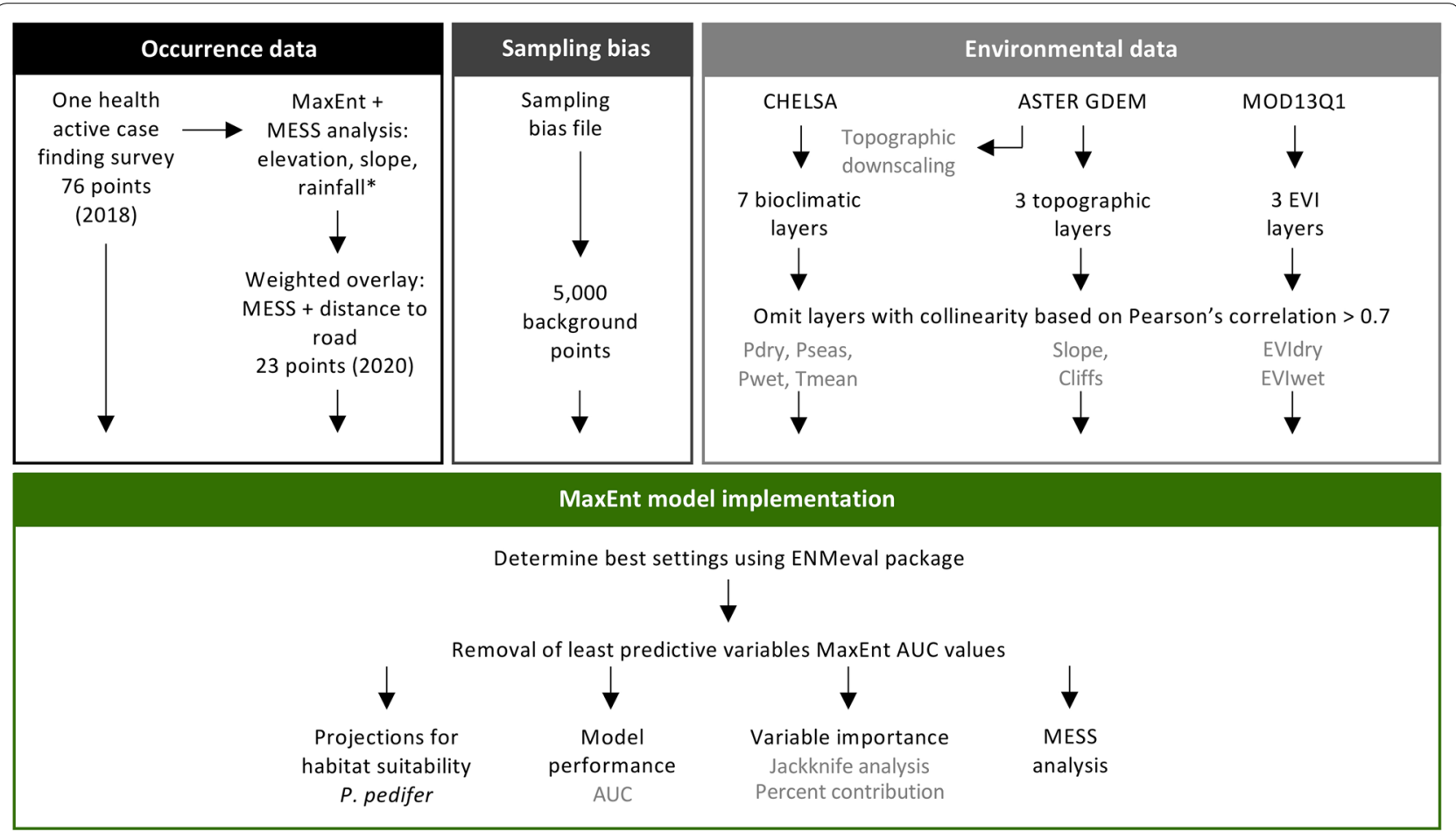

Fig. 2 Overview of the research data and methods. See Methods section for details. Abbreviations: MaxEnt, maximum entropy; MESS: multivariate environmental similarity surface; CHELSA, climatologies at high resolution for the earth's land surface areas; ASTER, advanced spaceborne thermal emission and reflection radiometer; GDEM, global digital elevation model; MOD13Q1, terra moderate resolution imaging spectroradiometer vegetation indices; EVI, enhanced vegetation index; Tmean, mean temperature; Pseas, precipitation seasonality; EVIdry, enhanced vegetation index in the dry season; Pdry, precipitation in the driest months; Pmean, mean precipitation; Cliffs, ordinal categorical values indicating cliffs between 20-40\% and above 40\%; EVIwet, enhanced vegetation index in the wet season; AUC, area under the curve 
$\operatorname{arcsec}(\sim 1 \mathrm{~km})[15,30]$. A subset of seven out of 19 available bioclimatic variables were considered ecologically relevant to the species and selected, in particular annual averages and extrema (minimum and maximum) for both temperature and precipitation and a variable describing the annual rainfall variation as a measure for seasonality [35].

The vector is breeding in caves on cliff walls, where hyraxes are living. Therefore, an ASTER digital elevation model (DEM) with $30 \mathrm{~m}$ spatial resolution was acquired from U.S. Geological Survey (USGS, earth explorer, https ://earthexplorer.usgs.gov/), of which the slope (percentage) was computed. To avoid losing the information about cliffs while resampling to a resolution of $250 \mathrm{~m}$, an additional ordinal categorical layer was created using a weighted overlay analysis, indicating number of slopes between $20-40 \%$ (25\% weight) and $>40 \%$ ( $75 \%$ weight) per $250 \mathrm{~m}$ pixel.

Sand flies require vegetation through which they can move, forage and reproduce [36]. Hence, vegetation layers were included as potential predictors from USGS. The Moderate Resolution Imaging Spectroradiometer (MODIS) enhanced vegetation index (EVI) quantifies the vegetation density. The MOD13Q1 product (https:// earthexplorer.usgs.gov/) is produced on a 16 days interval base and corrects for particular atmospheric conditions and canopy background noise. Indices were derived for the annual and seasonal averages over the past three years (2017-2019) with $250 \mathrm{~m}$ spatial resolution.

All environmental layers, the occurrence points and bias file were projected in the same spatial reference system, World Geodetic System 84 (WGS84 EPSG:4326)

\section{Topographic downscaling of climate layers}

The bioclimatic layers were downscaled on the basis of topographic variables to produce topoclimate (local climate at a particular topography) at high resolution as functionally relevant predictor variables [37]. We opted for a resolution of $250 \mathrm{~m}$ because it formed an appropriate balance between a feasible spatial resolution to guide implementation of vector control measures and the computational capacity required for the downscaling process. Downscaling followed a Geographically Weighted Regression (GWR) approach [38] outlined by Lenoir et al. [39] and was based on elevation, slope, northness, eastness, distance from the ocean and potential solar radiation. These predictor variables have shown good results for predicting temperature and precipitation data in previous studies [39-45].

Data were prepared for downscaling in $\mathrm{R}$ version 3.5.2 [46] using the raster package [47]. The area was subdivided into 16 sections to make the computation time for downscaling feasible for the size of our study site. Topographic variables were derived from the ASTER DEM at $250 \mathrm{~m}$ resolution. Distance from the ocean was downloaded from http://www.soest.hawaii.edu/pwessel/gshhg / at 1 arc-minute resolution [48]. The potential incoming solar radiation was calculated for each grid cell of the DEM for the spring equinox (March 21st) with a 6-hour resolution using the SAGA GIS 6.3.0 tool Potential Incoming Solar Radiation [49]. The downscaling was performed on resources provided by the NTNU IDUN/EPIC computing cluster using $\mathrm{R}$ version 3.6.0 and the spgwr package [50]. The 16 sections were mosaicked together and checked for correspondence to CHELSA values.

Table 1 Environmental layers acquired as candidate explanatory variables to predict the habitat suitability of Phlebotomus pedifer. CHELSA layers at 30 arc-seconds were downscaled and USGS slope and cliffs layers were resampled, all to a $250 \mathrm{~m}$ spatial resolution

\begin{tabular}{|c|c|c|c|c|}
\hline Name & Explanation & Source & $\begin{array}{l}\text { Original spatial } \\
\text { resolution }\end{array}$ & Data range study area \\
\hline Tmean & Annual mean temperature (Bio1) & CHELSA & 30 arcsec & $8-34^{\circ} \mathrm{C}$ \\
\hline Tmax & Maximum temperature of the warmest month (Bio5) & CHELSA & $30 \operatorname{arcsec}$ & $14-45^{\circ} \mathrm{C}$ \\
\hline Tmin & Minimum temperature of the coldest month (Bio6) & CHELSA & $30 \operatorname{arcsec}$ & $2-31^{\circ} \mathrm{C}$ \\
\hline PrecMean & Annual precipitation (Bio12) & CHELSA & 30 arcsec & $526-3216 \mathrm{~mm}$ \\
\hline PrecWet & Precipitation of the wettest month (Bio13) & CHELSA & 30 arcsec & $90-369 \mathrm{~mm}$ \\
\hline PrecDry & Precipitation of the driest month (Bio14) & CHELSA & 30 arcsec & $5-68 \mathrm{~mm}$ \\
\hline PrecSeas & Precipitation seasonality (Bio15) & CHELSA & 30 arcsec & $21-94 \%$ \\
\hline Slope & Hill slope calculated from elevation DEM & USGS & $30 \mathrm{~m}$ & $0-77 \%$ \\
\hline Cliffs & $\begin{array}{l}\text { Ordinal categorical value for number of slopes exceeding } 20 \% \text { and } 40 \% \\
\text { per pixel }\end{array}$ & USGS & $30 \mathrm{~m}$ & $1-9$ \\
\hline EVImean & Average EVI from January 2017 until December 2019 (MOD13Q1) & USGS & $250 \mathrm{~m}$ & $-0.13-0.59$ \\
\hline EVIdry & Average EVI for the dry season (January to March), MOD13Q1 & USGS & $250 \mathrm{~m}$ & $-0.99-0.60$ \\
\hline EVlwet & Average EVI for the wet season (July to September) (MOD13Q1) & USGS & $250 \mathrm{~m}$ & $-0.16-0.70$ \\
\hline
\end{tabular}


Single outliers due to small bandwidth of the GWR were removed and missing data were interpolated using the Close Gaps tool of SAGA.

\section{Variable preparation}

Overall, 12 environmental layers were considered to potentially predict the habitat suitability of $P$. pedifer (Table 1). All layers were resampled to match a $250 \mathrm{~m}$ spatial resolution. For aggregation of the slope variable, the maximum values were retained to prevent the loss of information on slope steepness, while for all other layers, average values were calculated.

Apart from ecological relevance, multi-collinearity among candidate predictor variables was assessed with a Pearson's correlation (Fig. 2, light grey frame, Additional file 1: Figure S1). If the absolute coefficient exceeded 0.7, one of the pair variables was omitted for inclusion in the model. This resulted in eight remaining candidate predictor variables: Tmean, Pmean, Pdry, Pseas, Slope, Cliffs, EVIdry and EVIwet.

\section{MaxEnt model implementation}

A model predicting the habitat suitability of $P$. pedifer was developed by a MaxEnt model using the dismo package in $\mathrm{R}$ version 3.3.1 [51].

The optimal settings for the MaxEnt model were determined using the ENMeval $\mathrm{R}$ package, in which the random 10-fold cross-validation data partitioning method was used (Fig. 2, green frame) [52, 53]. The function compares all possible model setting combinations and calculates the Akaike information criterion (AIC) value for each combination. The lowest AIC value was found for a model with a regularization multiplier of 0.5 , including linear and quadratic features and a combination of these classes. Hence, these settings were used to fit the model, which was run using a 10-fold cross-validation method, with $75 \%$ of the presences used for training and $25 \%$ for testing. Additionally, 5000 background points were assigned based on the bias file (Fig. 3).

A second round of variable selection was carried out by an iterative removal of the least predictive variables by the area under the curve (AUC) values of the receiver operator characteristic (ROC) of the MaxEnt model to maximize the model performance and minimize overfitting. Yet, all variables contributed considerably to a better model AUC, so the final model consisted of the following eight variables: Tmean, Pmean, Pdry, Pseas, Slope, Cliffs, EVIdry and EVIwet.

In order to assess the robustness of the final model, it was run 200 times, including new random background points in each run. Model accuracy was evaluated by calculating the average training and testing AUC values over 200 runs.
A MESS analysis was performed to indicate areas where model projections were extrapolated (Fig. 2, green frame). The relative importance of the variables to predict the habitat suitability of $P$. pedifer was assessed using the jackknife estimates and percent contributions.

\section{Results \\ Entomological survey}

The only Phlebotomus species that was captured during both entomological surveys was $P$. pedifer. The species was collected at altitudes ranging between 1685-2892 m and most were captured inside human dwellings, which was in most cases due to excessive rainfall impeding outdoor trapping.

\section{Prediction of suitable habitats for $P$. pedifer}

The predicted habitat suitability for $P$. pedifer based on the MaxEnt model is shown in Fig. 4a. The predictive performance of the model was high, with average $( \pm S D)$ training and testing AUC values being $0.93 \pm 0.01$ and $0.90 \pm 0.02$, respectively.

Generally, the conditions are predicted highly suitable for the vector in a 'belt' surrounding the main mountain ranges (Figs. 1b, 4a). This is most pronounced in Gamo zone and the eastern part of Gofa zone, where the highest mountain peaks are situated (Figs. 1b, c, 4a). In the central and western part of Gofa, Wolaita and Dawuro zones and Dherashe area, where mountains are generally lower, the predicted suitable habitats are more evenly distributed. In our study site, an area of $720 \mathrm{~km}^{2}(3.6 \%)$ was indicated with very suitable conditions for the presence of $P$. pedifer (>0.6), $674 \mathrm{~km}^{2}(3.4 \%)$ showed a habitat suitability value between $0.4-0.6$ and $1174 \mathrm{~km}^{2}(5.2 \%)$ between 0.2-0.4.

The MESS analysis (Fig. 4b) demonstrates that almost none of the predicted suitable areas were projections out of the range of the training variables (no extrapolation), supporting the credibility of the model. Negative values were observed particularly in the lowlands, where $P$. pedifer was not found during the entomological surveys.

\section{Environmental variables associated with vector presence}

The percent contributions (Fig. 5a, Additional file 2: Table S1) and jackknife test estimates (Fig. 5b) indicated that the most important variable to predict the habitat suitability of $P$. pedifer was the mean annual temperature variable, which had an average relative contribution $( \pm S D)$ of $60.0 \pm 3.0 \%$ to the model. The regularized training gain of the model with only and without the mean annual temperature were $0.83 \pm 0.06$ and $0.80 \pm 0.05$ ), respectively, of the total model training gain of $1.47 \pm 0.07$. The second most important variable 
was precipitation seasonality $(13.2 \pm 2.1)$, followed by the Enhanced Vegetation Index in the dry season, mean annual precipitation and precipitation in the dry season. The mean annual precipitation was slightly correlated with the precipitation seasonality (Additional file 1: Figure S1), causing the jackknife estimate for this variable only to be low. Cliffs and Slope variables had very low importance in the model.

The way the prediction depends on the two most important variables (mean annual temperature and precipitation seasonality) and their correlation with the other variables is presented in Fig. 6 (other variables in Additional file 3: Figure S2). The mean annual temperature variable indicated suitable habitats for yearly average temperatures ranging approximately between $12-20{ }^{\circ} \mathrm{C}$, reaching an optimum at about $16{ }^{\circ} \mathrm{C}$. A similar pattern was observed for the precipitation seasonality variable with an optimum at $50 \%$ precipitation variability.

\section{Discussion}

Identifying the vector distribution is pivotal for guidance of targeted integrated vector control, because places where $P$. pedifer occurs are either burdened by $\mathrm{CL}$ or vulnerable for a disease outbreak [54]. In this study, we designed a MaxEnt model resulting in a practical, highresolution map indicating areas suitable for the presence of $P$. pedifer in five zones in southwestern Ethiopia.

Previous studies pointed out that $P$. pedifer is the only vector for transmission of $L$. aethiopica in Ochollo village $[6,15,55]$. Our entomological surveys confirm this finding in a much larger area, as this was the only species of Phlebotomus captured in the five zones.

Our model predicts that suitable habitats for $P$. pedifer are situated in a 'belt' surrounding the slopes of the high mountain peaks, whereas it is more evenly distributed in lower mountainous areas. This is in contrast with previous studies which describe the distribution of $\mathrm{CL}$ in Ethiopia to occur in foci [7].

Although the variables selected for our model were thoughtfully selected, there could potentially be an additional microecological variable that was not included but could predict this focal distribution. Another likely explanation could be that our model predictions are accurate and the considered patchy distribution is a result of underreporting of CL because of various reasons, like misdiagnosis, lack of diagnostics and understanding of the importance of reporting cases etc. $[7,56]$.

Therefore, it is sometimes suggested to perform a field validation study to evaluate the accuracy of the model [54, 57-60]. However, it should be taken into account that not all individuals of a species live in optimal conditions, so it is possible to find the species outside the predicted suitable habitat [61]. Moreover, a species distribution can be constrained by dispersal limitations [62]. Also, even though generally the environmental conditions are permissive for the vector, it could be that there are no available blood or sugar sources or there are no niches for resting, breeding and survival of the vector within its flight range [63]. Therefore, neither finding some sand flies in areas that are not suitable for a species a

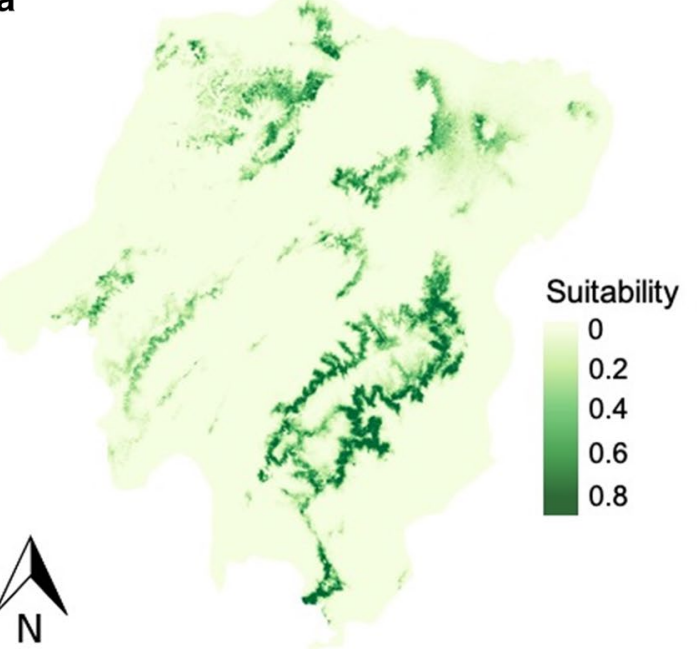

b

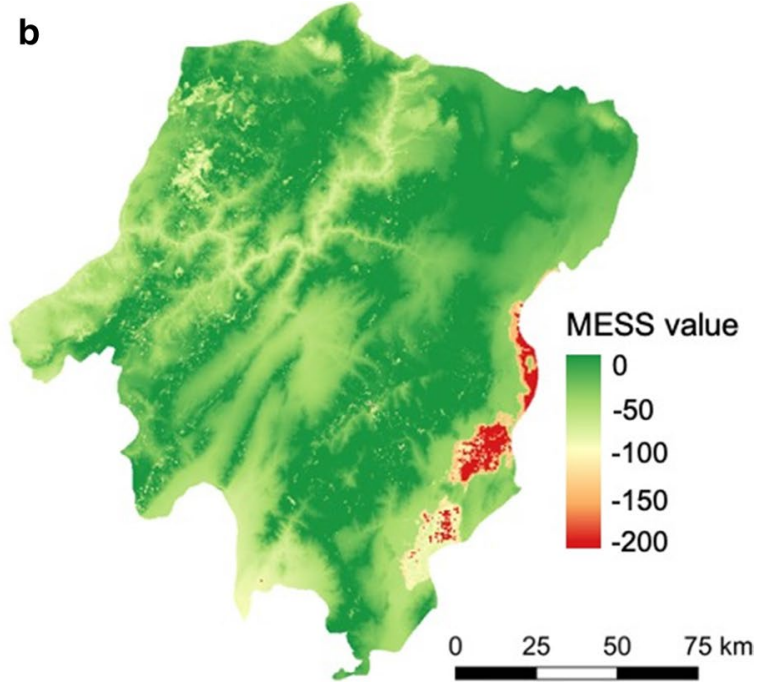

Fig. 4 Predicted suitable habitats for Phlebotomus pedifer using a MaxEnt model (a) and MESS analysis outcome (b). In the MESS map, values below zero are predictions slightly out of the range of the training variables. Areas indicated in red are the Abaya and Chamo lakes surrounding Arba Minch. Abbreviations: MaxEnt, maximum entropy; MESS, multivariate environmental surface similarity 

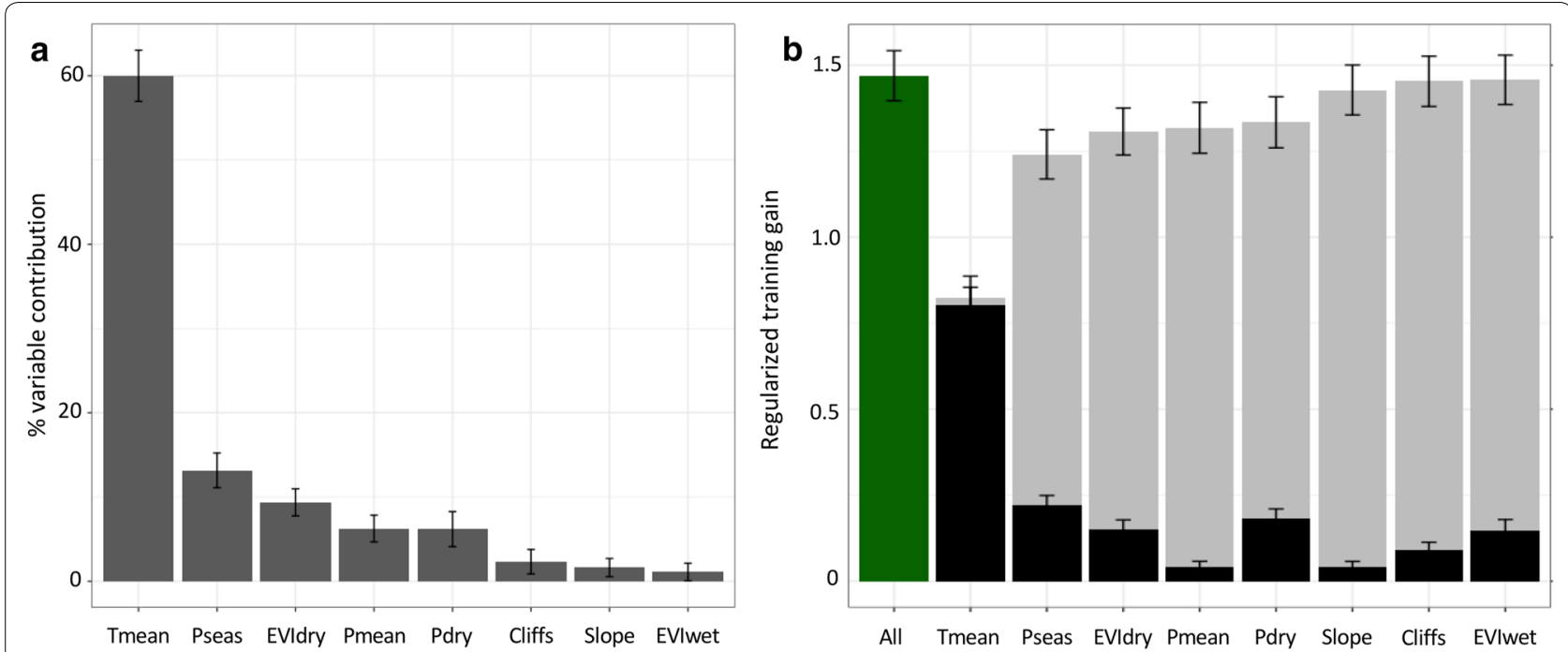

Fig. 5 Percent variable contribution (a) and jackknife estimates (b) of the MaxEnt habitat suitability of P. pedifer. The green bar is the total regulized training gain, grey bars are the model training gain without the variable and black bars with only the indicated variable. Abbreviations: Tmean, mean temperature; Pseas, precipitation seasonality; EVIdry, enhanced vegetation index in the dry season; Pdry, precipitation in the driest months; Pmean, mean precipitation; Cliffs, ordinal categorical values indicating cliffs between $20-40 \%$ and above $40 \%$; EVIwet, enhanced vegetation index in the wet season

nor not being able to capture sand flies in certain suitable habitats means the prediction is unreliable.

The obvious 'belt' around the higher mountains indicates that the environment is unsuitable for the presence of the vector up to and as of a certain height. In many studies, elevation is included as a response variable in the model $[16,19,64-66]$. However, this variable can have different environmental characteristics in different areas (depending on the slope, aspect, wind, etc.) and may thus result in overfitting of the model. Therefore, we used elevation, slope, aspect and distance to ocean as indirect measures of topoclimate.

We demonstrate that the mean annual temperature is by far the most important predictor for the presence of $P$. pedifer. The seasonality in precipitation also contributed considerably to the predictions. This means that lowland areas have too high temperatures and little variation in precipitation, while at high altitudes it is too cold and excessively raining in the wet season compared to the dry season for the vector to survive (Fig. 6). The importance
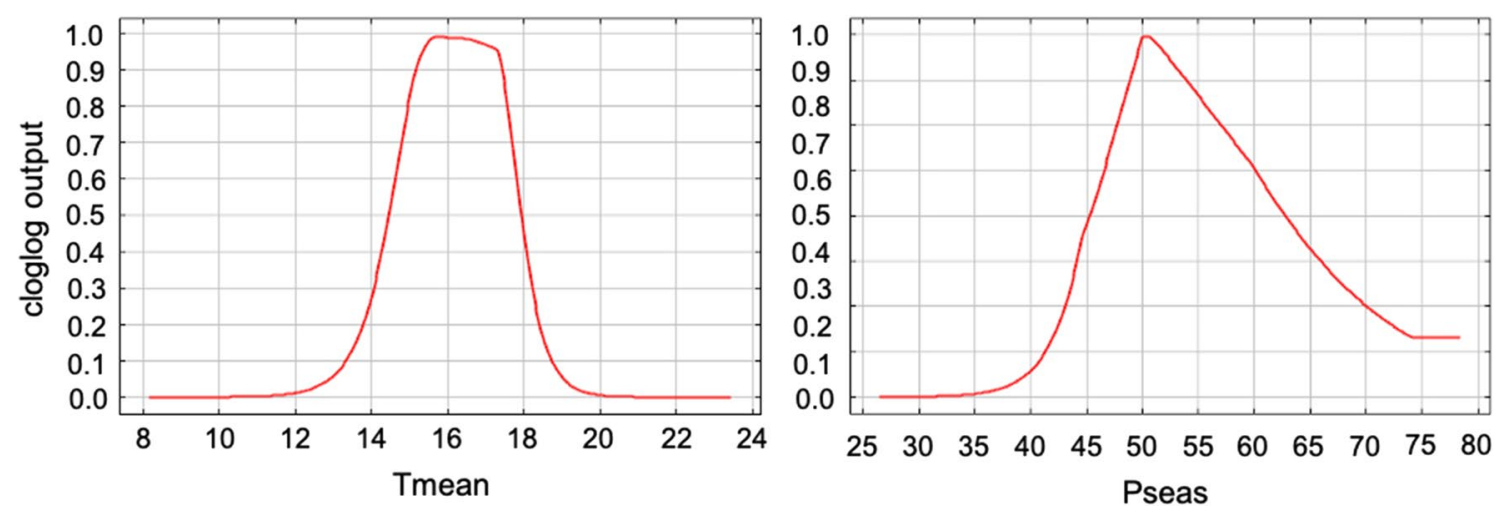

Fig. 6 Dependence of the predicted suitability on two most contributing variables. The curves show how the prediction changes as each environmental variable is varied, keeping all other environmental variables at their average sample value. The cloglog value provides an estimate between 0-1 of probability of presence. Abbreviations: Tmean, mean temperature; Pseas, precipitation seasonality 
of the climate variables is consistent with other studies mapping the distribution of leishmaniasis and its vectors [16, 63, 65-67].

Our previous findings in Ochollo village show that the abundance of the vector population is similarly correlated with temperature and humidity (as a proxy for rainfall) [15]. Ochollo lies at an altitude of 2100 metres with annual temperatures ranging between $17.0-22.6^{\circ} \mathrm{C}$. Phlebotomus pedifer is present in the village during the whole year, but less abundant in the wet season and infected sand flies were continuously present inside caves [15]. In villages at lower or higher altitudes, however, there is a distinct climate, thus the seasonality of the (infected) sand fly population probably differs from what is observed in Ochollo. Periods without infections in sand flies can occur because Leishmania requires particular temperatures for development in the vector [68]. Furthermore, sand fly larvae can diapause, waiting for several months for favorable environmental conditions to develop to an adult stage, resulting in months without any sand flies $[69,70]$. This phenomenon has been observed for P. orientalis, the main VL vector in Ethiopia, in the wet season [71]. Hence, we expect that the seasonality found in our previous paper would lead to periods without sand flies in the wet season in highland areas while sand flies can possibly only survive in the wet season in the lower highlands.

The importance of these climate variables could also indicate that the distribution of the vector could alter when the climate changes $[35,54,72]$. For Ethiopia, it is predicted that the temperature will rise, and rainfall will become erratic with flood and drought events likely to increase [73]. We hypothesize that therefore there could be a shift of $P$. pedifer presence towards the highlands. If these are places where people have no immunity due to parasite exposure yet and hyraxes are present to serve as reservoirs, this could lead to new outbreaks. It would be interesting for future studies to make a model with only microclimate variables and project the vector's potential niche to the future to assess what would happen to the distribution of the vector.

The variables Slope and Cliffs showed a low relative importance for the model. This was unexpected, as rock crevices in cliffs are the main breeding sites of $P$. pedifer and CL is positively correlated with proximity to caves and hyrax habitats $[7,13,15,74]$. This could potentially be a result of sampling that was mainly performed inside human dwellings instead of in outdoor sand fly breeding sites to avoid decreased trapping efficiency due to excessive rainfall. However, the selected houses for sand fly collection were often nearby potential sand fly and hyrax habitats. The study of Seid et al. [16] that predicted the area at risk for CL in Ethiopia, found slopes $>7.45$ degrees to be highly associated with CL presence, which corresponds with a slope $>13 \%$. Our model focused on steep slopes (20-40\% and >40\%) to represent cliffs as hyrax and sand fly habitats, which presumably explains why it was not important in our model.

In our previous study in Ochollo, we demonstrated that sand flies are mainly present inside caves, but considerable numbers and infected sand flies can also be found in stone fences around houses or in cracks of large boulders [15]. During the present entomological surveys, $P$. pedifer was trapped in some sites where no typical basalt cliffs with caves were observed. This suggests that caves may not be a crucial environment for sand fly presence as the model suggests, but rather enhance the abundance of the vector population. Knowledge on the distribution of basalt cliffs and caves at high resolution could perhaps provide a better insight into the importance of the cliffs for the presence of $P$. pedifer.

Previous distribution maps were already made for the distribution of CL cases and VL vectors (P. orientalis and P. martini) in Ethiopia $[16,63]$. The former was designed by Seid et al. [16] using a multivariate logistic regression analysis to assess the most important predictor variables and a probabilistic and weighted overlay analysis to generate a risk map for CL. They found elevation, rainfall and slope as the most important predictors of CL distribution and the map indicates more than one fifth of the country at high or highest risk for CL. Even peak highlands $(>2650 \mathrm{~m})$ were indicated at highest risk and lowland areas were still medium to low risk areas. This deviates from our results, where only about $7 \%$ of the mountainous study area had favorable conditions (suitability $>0.4$ ) for survival of $P$. pedifer.

Although other methods were applied in that study, logically their map should overlap with ours of the distribution of the vector. We have visited the lowland and peak highland areas, but $P$. pedifer was only found between 1685-2892 m. Our results correspond with the reported CL endemic sites which were never situated at such high or low altitudes [5, 6, 9-13]. The authors indicate in their paper that the predictions at these altitudes are indeed odd but might be due to a recent change in vector behavior [16]. However, our study demonstrates that the vector does also not occur there and therefore suggests that their map overestimates the distribution of CL drastically.

Other studies modeling the distribution of vectors commonly use a $1 \mathrm{~km}$ spatial resolution because climate layers are only available at this coarse resolution $[65,66$, 75-77]. Because climate variables are often the most important predictors for SDMs of disease vectors, these data should be very detailed [35, 65, 66, 75]. Moreover, 
recently SDMs are being used for optimization of vector control, so it is beneficial for coordination of resource allocation for targeted control measures to have smaller grids indicating the suitable habitats of the vector [17]. To our knowledge, our study is the first to implement downscaled climate variables (topoclimate) to model the distribution of sand flies in a mountainous area at fine resolution.

\section{Conclusions}

Overall, this study indicates that the mean annual temperature is the most important predictor for the spatial distribution of $P$. pedifer. We demonstrate that about $7 \%$ of the study area is suitable for the presence of the vector and show with a high-resolution map, the localities that should be focused on for implementation of integrated vector control measures, which are mainly located at mid-highland altitudes.

\section{Supplementary information}

Supplementary information accompanies this paper at https://doi. org/10.1186/s13071-020-04336-3.

Additional file 1: Figure S1. Output of the Pearson's correlation analysis to reduce multi-collinearity of the variables.

Additional file 2: Table S1. Percent variable contribution and jackknife estimates indicating the most important variables for the model. Abbreviations: SD, standard deviation; Tmean, mean temperature; Pseas, precipitation seasonality; EVIdry, enhanced vegetation index in the dry season; Pdry, precipitation in the driest months; Pmean, mean precipitation; Cliffs, ordinal categorical values indicating cliffs between $20-40 \%$ and above 40\%; EVlwet, enhanced vegetation index in the wet season.

Additional file 3: Figure S2. Dependence of the predicted suitability on the six least contributing variables. The curves show how the prediction changes as each environmental variable is varied, keeping all other environmental variables at their average sample value. The cloglog value provides an estimate between 0 and 1 of probability of presence. Abbreviations: EVldry, enhanced vegetation index in the dry season; Pdry, precipitation in the driest months; Pmean, mean precipitation; Cliffs, ordinal categorical values indicating cliffs between $20-40 \%$ and above 40\%; EVlwet, enhanced vegetation index in the wet season.

\section{Abbreviations}

AUC: Area under the curve; CHELSA: Climatologies at High resolution for Rarth's Land Surface Areas; CL: Cutaneous leishmaniasis; DEM: Digital elevation model; EVI: Enhanced vegetation index; MaxEnt: Maximum entropy; MCL: Mucocutaneous leishmaniasis; MESS: Multivariate, environmental similarity surfaces; MODIS: Moderate resolution imaging spectroradiometer; NTD: Neglected tropical diseases; ROC: Receiver operator characteristic; SDM: Species distribution model; SNNPR: Southern Nations, Nationalities and Peoples' Region; USGS: U.S. Geological Survey; VL: Visceral leishmaniasis; WGS: World geodetic system.

\section{Acknowledgements}

We are very grateful to all NTD focal persons and health extension workers for their guidance and support during the field work. We also thank staff of Arba Minch University, zonal and district health offices for their arrangements to accomplish the field work. Furthermore, we acknowledge Jonas Lembrechts from the University of Antwerp for his advice on the model analyses.

\section{Authors' contributions}

MP, AR and HL designed the study. MP, BM, NG, SS and LR coordinated and carried out the field work. MP, NG and LR carried out the sand fly dissections. $M P, A R, B M$ and REMW analyzed and interpreted the data and wrote the initial manuscript. HL participated in the coordination and revised the manuscript. All authors read and approved the final manuscript.

\section{Funding}

MP is a PhD fellow in the VLADOC Programme of the Flemish Interuniversity Council VLIR-UOS (NDOC2016PR003). HL is part of the University of Antwerp Center of Excellence VAX-IDEA. BM and the study were supported by VLIR-UOS through the Inter-University Cooperation (IUC) agreement with Arba Minch University (AMU ET2017IUC035A101).

\section{Availability of data and materials}

The datasets analyzed during the present study are available from the corresponding authors upon reasonable request.

\section{Ethics approval and consent to participate}

The survey was ethically approved by the Institutional Ethical Review Committee of the College of Medicine and Health Sciences of Arba Minch University, Ethiopia (CMHS/1167/111). Samples were collected from human dwellings after participants gave their oral consent.

\section{Consent for publication}

Not applicable.

\section{Competing interests}

The authors declare that they have no competing interests.

\section{Author details}

${ }^{1}$ Evolutionary Ecology Group, University of Antwerp, Antwerp, Belgium. ${ }^{2}$ Public Health Department, Arba Minch University, Arba Minch, Ethiopia. ${ }^{3}$ Department of Biology, Norwegian University of Science and Technology, Trondheim, Norway. ${ }^{4}$ Biology Department, Arba Minch University, Arba Minch, Ethiopia.

Received: 16 June 2020 Accepted: 1 September 2020

Published online: 11 September 2020

\section{References}

1. Maroli M, Feliciangeli M, Bichaud L, Charrel R, Gradoni L. Phlebotomine sandflies and the spreading of leishmaniases and other diseases of public health. Med Vet Entomol. 2013;27:123-47.

2. Center of Disease Control and Prevention. Parasites - Leishmaniasis. 2013. https://www.cdc.gov/parasites/leishmaniasis/biology.html. Accessed 7 Sep 2018.

3. Alvar J, Yactayo S, Bern C. Leishmaniasis and poverty. Trends Parasitol. 2006;22:552-7.

4. Alvar J, Vélez ID, Bern C, Herrero M, Desjeux P, Cano J, et al. Leishmaniasis worldwide and global estimates of its incidence. PLOS ONE. 2012;7:e35671.

5. Lemma W, Erenso G, Gadisa E, Balkew M, Gebre-Michael T, Hailu A. A zoonotic focus of cutaneous leishmaniasis in Addis Ababa, Ethiopia. Parasit Vectors. 2009;2:60.

6. Ashford W, Bray M, Hutchinson P, Bray S. The epidemiology of cutaneous leishmaniasis in Ethiopia. Trans R Soc Trop Med Hyg. 1973;67:568-601.

7. van Henten S, Adriaensen W, Fikre H, Akuffo H, Diro E, Hailu A, et al. Cutaneous leishmaniasis due to Leishmania aethiopica. EClinicalMedicine. 2018;65:69-81.

8. WHO. Global Health Observatory data repository. Geneva: World Health Organization; 2019.

9. Bugssa G, Hailu A, Demtsu B. The current status of cutaneous leishmaniasis and the pattern of lesions in Ochollo primary school students, Ochollo, southwestern Ethiopia. Sci J Clin Med. 2014;3:111-6.

10. Mengistu G, Laskay T, Gemetchu T, Humber D, Ersamo M, Eva D, et al. Cutaneous leishmaniasis in south-western Ethiopia: Ocholo revisited. Trans R Soc Trop Med Hyg. 1992;86:149-53.

11. Negera E, Gadisa E, Yamuah L, Engers H, Hussein J, Kuru T, et al. Outbreak of cutaneous leishmaniasis in Silti woreda, Ethiopia: risk factor 
assessment and causative agent identification. Trans R Soc Trop Med Hyg. 2008;102:883-90.

12. Lemma A, Foster W, Gemetchu T, Preston P, Bryceson A, Minter D. Studies on leishmaniasis in Ethiopia. I. Preliminary investigation into the epidemiology of cutaneous leishmaniasis in the highlands. Ann Trop Med Parasitol. 1969;63:455-72.

13. Bsrat A, Berhe N, Balkew M, Yohannes M, Teklu T, Gadisa E, et al. Epidemiological study of cutaneous leishmaniasis in Saesie Tsaeda-emba district, eastern Tigray, northern Ethiopia. Parasit Vectors. 2015:8:149

14. Pareyn M, Kochora A, Van Rooy L, Eligo N, Vanden Broecke B, Girma N, et al. Feeding behavior and activity of Phlebotomus pedifer and potential reservoir hosts of Leishmania aethiopica in southwestern Ethiopia. PLoS Negl Trop Dis. 2020;14:e0007947.

15. Pareyn M, Van den Bosch E, Girma N, van Houtte N, Van Dongen S, Van der Auwera G, et al. Ecology and seasonality of sandflies and potential reservoirs of cutaneous leishmaniasis in Ochollo, a hotspot in southern Ethiopia. PLoS Negl Trop Dis. 2019;13:e0007667.

16. Seid A, Gadisa E, Tsegaw T, Abera A, Teshome A, Mulugeta A, et al. Risk map for cutaneous leishmaniasis in Ethiopia based on environmental factors as revealed by geographical information systems and statistics. Geospat Health. 2014;8:377-87.

17. Dicko AH, Lancelot R, Seck MT, Guerrini L, Sall B, Lo M, et al. Using species distribution models to optimize vector control in the framework of the tsetse eradication campaign in Senegal. Proc Natl Acad Sci USA. 2014;111:10149-54.

18. Guisan A, Thuiller W. Predicting species distribution: offering more than simple habitat models. Ecol Lett. 2005;8:993-1009.

19. Jiménez-Valverde A, Peterson AT, Soberón J, Overton JM, Aragón P, Lobo JM. Use of niche models in invasive species risk assessments. Biol Invasions. 2011;13:2785-97.

20. Hijmans RJ, Cameron SE, Parra JL, Jones G, Jarvis A. Very high resolution interpolated climate surfaces for global land areas. Int I Climatol. 2005:25:1965-78

21. Warren DL, Glor RE, Turelli M. Environmental niche equivalency versus conservatism: quantitative approaches to niche evolution. Evolution. 2008:62:2868-83.

22. González-Moreno P, Diez JM, Richardson DM, Vilà M. Beyond climate: disturbance niche shifts in invasive species. Glob Ecol Biogeogr. 2015;24:360-70.

23. Bramer I, Anderson BJ, Bennie J, Bladon A, De Frenne P, Hemming D, et al. Advances in monitoring and modelling climate at ecologically relevant scales. Adv Ecol Res. 2018:58:101-61.

24. Lembrechts JJ, Nijs I, Lenoir J. Incorporating microclimate into species distribution models. Ecography. 2019;42:1267-79.

25. Gottfried M, Pauli H, Reiter K, Grabherr G. A fine-scaled predictive model for changes in species distribution patterns of high mountain plants induced by climate warming. Divers Distrib. 1999;5:241-51.

26. Holden ZA, Abatzoglou JT, Luce CH, Baggett LS. Empirical downscaling of daily minimum air temperature at very fine resolutions in complex terrain. Agric For Meteorol. 2011;151:1066-73.

27. Geiger R, Aron RH, Todhunter P. The climate near the ground. Lanham: Rowman and Littlefield Publishers; 2003.

28. Slavich E, Warton DI, Ashcroft MB, Gollan JR, Ramp D. Topoclimate versus macroclimate-how does climate mapping methodology affect species distribution models and climate change projections? Divers Distrib. 2014;20:952-63.

29. Meineri E, Hylander K. Fine-grain, large-domain climate models based on climate station and comprehensive topographic information improve microrefugia detection. Ecography. 2017;40:1003-13.

30. Karger DN, Conrad O, Böhner J, Kawohl T, Kreft H, Soria-Auza RW, et al. Climatologies at high resolution for the earth's land surface areas. Sci Data. 2017:4:170122.

31. Lewis DJ, Mutinga MJ, Ashford RW. Phlebotomus longipes Parrot \& Martin (Diptera: Phlebotomidae) and a new related species. J Entomol. 1972:41:119-24.

32. Killick-Kendrick R, Tang Y, Killick-Kendrick M, Johnson RN, Ngumbi P, Sang D, et al. Phlebotomine sandflies of Kenya (Diptera: Psychodidae). III. The identification and distribution of species of the subgenus Larroussius. Ann Trop Med Parasitol. 1994;88:183-96.
33. Lewis DJ, Minter DM, Ashford RW. The subgenus Larroussius of Phlebotomus (Diptera, Psychodidae) in the Ethiopian region. Bull Entomol Res. 1974:64:435-42.

34. Kramer-schadt S, Lindenborn J, Reinfelder V, Stillfried M, Schr B, Heckmann I, et al. The importance of correcting for sampling bias in MaxEnt species distribution models. Divers Distrib. 2013;19:1366-79.

35. Chalghaf B, Chemkhi J, Mayala B, Harrabi M, Benie GB, Michael E, et al. Ecological niche modeling predicting the potential distribution of Leishmania vectors in the Mediterranean basin: impact of climate change. Parasit Vectors. 2018;11:461.

36. Chanampa M, Gleiser R, Hoyos C, Copa G, Mangudo C, Nasser J, et al. Vegetation cover and microspatial distribution of sand flies (Diptera: Psychodidae) in an endemic locality for cutaneous leishmaniasis in northern Argentina. J Med Entomol. 2018;55:1431-9.

37. Elith J, Leathwick JR. Species distribution models: ecological explanation and prediction across space and time. Annu Rev Ecol Evol Syst. 2009:40:677-97.

38. Lu B, Charlton M, Fotheringham AS. Geographically weighted regression using a non-Euclidean distance metric with a study on London house price data. Procedia Environ Sci. 2011;7:92-7.

39. Lenoir J, Hattab T, Pierre G. Climatic microrefugia under anthropogenic climate change: implications for species redistribution. Ecography. 2017:40:253-66.

40. Fridley J. Downscaling climate over complex terrain: high finescale $(<1000 \mathrm{~m})$ spatial variation of near-ground temperatures in a montane forested landscape (Great Smoky Mountains). J Appl Meteorol Climatol. 2009:48:1033-49.

41. Dobrowski SZ. A climatic basis for microrefugia: the influence of terrain on climate. Glob Chang Biol. 2011;17:1022-35.

42. Mair A, Fares A. Comparison of rainfall interpolation methods in a mountainous region of a tropical island. J Hydrol Eng. 2011:16:371-83.

43. Mallick J, Singh RK, Khan RA, Singh CK, Kahla NB, Warrag E, et al. Examining the rainfall-topography relationship using non-stationary modelling technique in semi-arid Aseer region, Saudi Arabia. Arab J Geosci. 2018:11:215.

44. Buytaert W, Celleri R, Willems P, De Bièvre B, Wyseure G. Spatial and temporal rainfall variability in mountainous areas: a case study from the south Ecuadorian Andes. J Hydrol. 2006:329:413-21.

45. Ashcroft MB, Gollan JR. Fine-resolution (25 m) topoclimatic grids of near-surface $(5 \mathrm{~cm})$ extreme temperatures and humidities across various habitats in a large $(200 \times 300 \mathrm{~km})$ and diverse region. Int J Climatol. 2012:32:2134-48

46. R Development Core Team. R: A language and environment for statistical computing. Vienna: R Foundation for Statistical Computing; 2018. https:// www.R-project.org/.

47. Hijmans R, van Etten J, Sumner M, Cheng J, Beva A, Bivand R, et al. raster: geographic data analysis and modeling. 2020. https://cran.r-project.org/ web/packages/raster/index.html.

48. Wessel P, Wmith W. A global self-consistent, hierarchical, high-resolution geography database, version 2.3.7. http://www.soest.hawaii.edu/pwess el/gshhg/.

49. Conrad O, Bechtel B, Bock M, Dietrich H, Fischer E, Gerlitz L, et al. System for Automated Geoscientific Analyses (SAGA) v. 2.1.4. Geosci Model Dev. 2015;8:1991-2007.

50. Bivand R, Yu D, Nakaya T, Garcia-Lopez M. spgwr: Geograhpically Weighted Regression. 2020. https://cran.r-project.org/web/packages/ spgwr/vignettes/GWR.pdf.

51. Hijmans R, Phillips S, Leathwick J, Elith J. Dismo: species distribution modeling. 2017. https://cran.r-project.org/web/packages/dismo/vigne ttes/sdm.pdf

52. Muscarella R, Galante P, Soley-Guardia M, Boria R, Kass J, Uriarte M, et al. Automated Runs and Evaluations of Ecological Niche Models. 2018. https://cran.r-project.org/web/packages/ENMeval/.

53. Muscarella R, Galante PJ, Soley-guardia M, Boria RA, Kass JM, Anderson RP. ENMeval: an R package for conducting spatially independent evaluations and estimating optimal model complexity for MAXENT ecological niche models. Methods Ecol Evol. 2014;5:1198-205.

54. Carvalho BM, Rangel EF, Vale MM. Evaluation of the impacts of climate change on disease vectors through ecological niche modelling. Bull Entomol Res. 2020;107:419-30. 
55. Gemetchu T, Laskay T, Frommel D. Phlebotomine sandflies (Diptera: Psychodidae, Phlebotominae) of Ochollo, southwestern Ethiopia: species composition and natural infection of Phlebotomus pedifer with Leishmania aethiopica. Ethiop J Sci. 1990;13:43-50.

56. Balzer R, Destombes $P$, Schaller K, Serie C. Leishmaniose cutanée pseudolepromateuse en Ethiopie. Bull Soc Pathol Exot. 1960;53:293-8.

57. Costa GC, Nogueira C, Machado RB, Colli GR. Sampling bias and the use of ecological niche modeling in conservation planning: a field evaluation in a biodiversity hotspot. Biodivers Conserv. 2010;19:883-99.

58. Searcy CA, Shaffer HB. Field validation supports novel niche modeling strategies in a cryptic endangered amphibian. Ecography. 2014;37:983-92.

59. Mothes CC, Searcy CA, Stroud JT, Clements SL, Searcy C. Evaluating ecological niche model accuracy in predicting biotic invasions using south Florida's exotic lizard community. J Biogeogr. 2019;46:432-41.

60. Aghaei Afshar A, Hojjat F, Yaghoobi-Ershadi MR, Rassi Y, Akhavan AA Gorouhi MA, et al. Modelling and evaluating the risk of zoonotic cutaneous leishmaniasis in selected areas of Kerman Province, south of Iran. Transbound Emerg Dis. 2020;67:1271-83.

61. Pulliam R. Sources, sinks and population regulation. Am Nat. 1988;132:652-61.

62. Lobo JM, Jime A. The uncertain nature of absences and their importance in species distribution modelling. Ecography. 2010;33:103-14

63. Gebre-Michael T, Malone JB, Balkew M, Ali A, Berhe N, Hailu A, et al. Mapping the potential distribution of Phlebotomus martini and P. orientalis (Diptera: Psychodidae), vectors of kala-azar in east Africa by use of geographic information systems. Acta Trop. 2004;90:73-86.

64. Rödder D, Lötters S. Niche shift versus niche conservatism? Climatic characteristics of the native and invasive ranges of the Mediterranean house gecko (Hemidactylus turcicus). Glob Ecol Biogeogr. 2009;18:674-87.

65. Meneguzzi VC, Leite GR, Fux B. Environmental niche modelling of phlebotomine sand flies and cutaneous leishmaniasis identifies Lutzomyia intermedia as the main vector species in southeastern Brazil. PLoS ONE. 2016;11:e0164580.

66. Signorini M, Cassini R, Drigo M, Frangipane A, Pietrobelli M, Montarsi F, et al. Ecological niche model of Phlebotomus perniciosus, the main vector of canine leishmaniasis in north-eastern Italy. Geospat Health. 2014;9:193-201.

67. Hanafi-Bojd AA, Yaghoobi-Ershadi MR, Haghdoost AA, Akhavan AA, Rassi Y, Karimi A, et al. Modeling the distribution of cutaneous leishmaniasis vectors (Psychodidae: Phlebotominae) in Iran: a potential transmission in disease prone areas. J Med Entomol. 2015;52:557-65.

68. Hlavacova J, Votypka J, Volf P. The effect of temperature on Leishmania (Kinetoplastida: Trypanosomatidae) development in sand flies. J Med Entomol. 2013;50:955-8.

69. Ready PD. Biology of phlebotomine sand flies as vectors of disease agents. Annu Rev Entomol. 2013;58:227-50.

70. Killick-Kendrick R. The biology and control of phlebotomine sand flies. Clin Dermatology. 1999;17:179-89.

71. Gebresilassie A, Kirstein OD, Yared S, Aklilu E, Moncaz A, Tekie H, et al. Species composition of phlebotomine sand flies and bionomics of Phlebotomus orientalis (Diptera: Psychodidae) in an endemic focus of visceral leishmaniasis in Tahtay Adiyabo district, northern Ethiopia. Parasit Vectors. 2015;8:248.

72. Ready PD. Leishmaniasis emergence and climate change. Rev Sci Tech. 2008;27:399-412

73. Simane B, Beyene H, Deressa W, Kumie A, Berhane K, Samet J. Review of climate change and health in Ethiopia: status and gap analysis. Ethiop J Heal Dev. 2016;30:28-41.

74. Girmay T, Teshome Z, Mahari M. Knowledge, attitude and practices of peasants towards hyraxes in two selected church forests in Tigray. J Biodivers Conserv. 2015;7:299-307.

75. Sallam MF, Xue R, Pereira RM, Koehler PG. Ecological niche modeling of mosquito vectors of West Nile virus in St. John's. Parasit Vectors. 2016;9:371.

76. Richman R, Diallo D, Diallo M, Sall AA, Faye O, Diagne CT, et al. Ecological niche modeling of Aedes mosquito vectors of chikungunya virus in southeastern Senegal. Parasit Vectors. 2018;11:255

77. Zaidi F, Fatima SH, Jan T, Fatima M, Ali A, Khisroon M, et al. Environmental risk modelling and potential sand fly vectors of cutaneous leishmaniasis in Chitral district: a leishmanial focal point of mount Tirich Mir, Pakistan. Trop Med Int Heal. 2017;22:1130-40.

78. OpenAFRICA: Ethiopia shapefiles. 2016. https://africaopendata.org/datas et/ethiopia-shapefiles.

79. QGIS Development team. QGIS Geographic Information System. Open Source Geospatial Foundation Project; 2019. http://qgis.osgeo.org.

\section{Publisher's Note}

Springer Nature remains neutral with regard to jurisdictional claims in published maps and institutional affiliations.
Ready to submit your research? Choose BMC and benefit from:

- fast, convenient online submission

- thorough peer review by experienced researchers in your field

- rapid publication on acceptance

- support for research data, including large and complex data types

- gold Open Access which fosters wider collaboration and increased citations

- maximum visibility for your research: over $100 \mathrm{M}$ website views per year

At BMC, research is always in progress.

Learn more biomedcentral.com/submissions 